\title{
The role of social media in reducing stigma and discrimination
}

Victoria Betton, Rohan Borschmann, Mary Docherty, Stephen Coleman, Mark Brown and Claire Henderson

\section{Summary}

This editorial explores the implications of social media practices whereby people with mental health problems share their experiences in online public spaces and challenge mental health stigma. Social media enable individuals to bring personal experience into the public domain with the potential to affect public attitudes and mainstream media. We draw tentative conclusions regarding the use of social media by campaigning organisations.

\section{Declaration of interest}

None.

\section{Copyright and usage}

(c) The Royal College of Psychiatrists 2015.
Victoria Betton (pictured) is a PhD student at the Institute of Communications, University of Leeds and is employed by Leeds and York Partnership NHS Foundation Trust as an mHealth programme director. Rohan Borschmann is a postdoctoral researcher at King's College London, Institute of Psychiatry, Psychology and Neurology. Mary Docherty is a NIHR academic clinical fellow at King's College London, Institute of Psychiatry, Psychology and Neurology. Stephen Coleman is Professor of Political Communication at the Institute of Communications, University of Leeds. Mark Brown is the development director of Social Spider $\mathrm{CIC}$ and the editor of One in Four magazine. Claire Henderson is a clinical senior lecturer in psychiatry in the Health Service and Population Research Department at King's College London, Institute of Psychiatry, Psychology and Neurology.

\section{Social media use by individuals to challenge stigma}

Social media can be defined as internet-based applications that allow the creation and exchange of user-generated content. Recent Ofcom ${ }^{2}$ figures indicate that $47 \%$ of the adult population in the UK use social media. However, low income families and disabled people are less likely to use the internet, ${ }^{1}$ raising concerns that people who are already marginalised are less likely to be heard.

Despite the barriers for some, social media are inexpensive and easy to use. They signify a trend towards more interaction whereby people create as well as consume content. It is possible to share stories, produce other content and influence the media environment. ${ }^{3}$ We argue that it is individuals, rather than institutions, who are leading the way in bringing conversations about mental health into public online spaces. We believe this is important to highlight, as the more negative affordances of social media are often emphasised. Although social media encompass many different channels, we have selected case studies that illustrate how the micro-blogging platform Twitter has been used to challenge stigma. Twitter is an internet application that allows 140-character messages to be publicly sent and quickly shared across many users.

Methods for challenging mental health stigma include education, contact and protest. ${ }^{4}$ Education replaces stereotypes with accurate facts and figures; personal contact between members of a stigmatised group and others undermines prevailing stereotypes; protest highlights injustice and rebukes stigmatising attitudes. Interaction on Twitter about mental health features a dynamic blend of these approaches, with personal narratives at the core.
A striking illustration of how social media can be used by people with mental health problems to challenge stigma is a protest on Twitter that took place in September 2013. Thousands of people, offended by the 'mental patient' Halloween costume advertised on the website of the national supermarket Asda's George clothing collection, sent tweets to show their disapproval. ${ }^{5}$ The topic 'went viral' with tweets passed rapidly and across networks. The story was the lead item on national news the next day with mainstream media sourcing their information from Twitter. ${ }^{5}$ Asda and other retailers removed the costumes from sale, apologised, and made donations to England's 'Time to Change' anti-stigma campaign.

During the protest, a \#mentalpatient hashtag was created by people with lived experience. They posted photographs of themselves ('selfies') alongside text such as 'this is what a real mental patient looks like', to satirise the costume. The hashtag, which creates a searchable string, was used 6694 times in $24 \mathrm{~h}$. The sharing of tweets by thousands of people may create a sense of solidarity, as well as minimising a recognised limitation of 'direct contact', namely discounting the experience of one or a few people as an exception, rather than the norm. ${ }^{6}$ When scores of people use a common hashtag it may be harder to ignore or minimise their experience.

The protest was initiated by individuals on Twitter and later backed by campaigning organisations. They amplified the conversation and exploited journalistic interest so that the story was taken into traditional media channels. Participants included individuals with lived experience of mental health problems, activists, journalists, public figures, charities and institutions. The event suggests a willingness by many people personally affected by mental health issues to voice their protest and to share their experiences publically. The extent to which such incidents have a positive effect on wider public attitudes has yet to be measured, but it certainly illustrates an effect on the actions of several corporations.

A striking aspect of social media sites such as Twitter is that a spontaneous burst of protest can be initiated by one individual in a single post and widely shared. The \#DearMentalHealthProfessionals hashtag was started on Twitter in early August 2013 by Amanda after receiving a discharge letter from her mental health team. She used the hashtag to voice her distress and the feedback she would like to give to the team. It was quickly shared and added to by a diverse mix of people with experience of using mental health services. Although modest in comparison with the Asda 
episode, it reached more people than would be readily possible through non-virtual means. One practitioner tweeted: 'This is the info my team needs to know. Am going to use it in my team meeting. This tweet indicates how online content can be spread to an offline environment. The motivation behind hashtags is not necessarily as simple as a desire to make services better; sharing experiences and having one's voice heard on social channels can create a sense of empowerment - of feeling less alone with a personal struggle, and more confidence in showing a part of the self that might usually remain hidden.

Helen, a mental health nurse, shared her experience as a psychiatric in-patient on Twitter out of both 'boredom and frustration' and to elicit support she felt she was not receiving from ward staff: 'it was quite a surreal experience . . . all these people who we'd [Helen and her partner] never met, reaching out and supporting us - people who'd used services before, people who were carers, people who were professionals and people who never had anything to do with mental health ever, but just were for some reason touched by what I was tweeting and were interested'. As well as gaining support and validation, Helen was also motivated by challenging mental health stigma. She reached people she would never otherwise have had contact with, as illustrated by the 800 new followers she gained on Twitter during the week, the re-tweets and the supportive responses she received. This is another example of how direct contact on social media enables sharing beyond the boundaries of face-to-face interactions and can connect with new audiences.

\section{Anti-stigma programmes' use of social media}

Social media channels are increasingly used by anti-stigma programmes to share their work and influence public attitudes. New Zealand's 'Like Minds, Like Mine' Facebook page entitled 'Stigma Watch' allows members to post and discuss media articles of concern because of their stigmatising content, thereby providing a space for conversation.

'Beyondblue', Australia's national depression and anxiety initiative, uses the hashtag \#SmashTheStigma whenever stories of hope and recovery are posted, and has led to others using the hashtag to share anti-stigma efforts.

The Swedish anti-stigma campaign 'Hjärnkoll' has 65 bloggers who write about mental health. When researching this editorial, Hjärnkoll's communications officer asked Facebook fans how social media can challenge stigma; in 3 days it was viewed by more than 5000 people, received 225 'likes', 77 comments and was shared 41 times. One respondent observed that, by providing people with the ability to 'peek through the window' surrounding mental distress, social media is 'a great way for people to digest mental illness in their immediate surroundings without having to be overpowered by social discomfort'. The 'Time to Change' campaign was launched in England in 2008. At the time of writing, the campaign has 57467 followers on Twitter with 224 re-tweets of the most recent post; and 129000 fans on Facebook with 431 likes on the most recent status update. These figures indicate a significant number of people with whom the campaign can connect regularly, and high levels of interaction with posts that can amplify their cause.

Along with advertisements on YouTube, Spain's 'Obertament' campaign uses Facebook and Twitter to inform people about their efforts to eradicate stigma. Denmark's 'En Af Os' campaign's Facebook page has attracted 16398 'likes', making it the country's second highest ranking website about mental health. Figures show that 'feel good' photos about mental health attract more shares than anything else posted on the page.
More sophisticated use of social media monitoring will see campaigns increasingly anticipating and responding quickly to mental health topics being discussed by individuals on social media channels, as well as benchmarking and measuring their activity.

\section{Conclusions}

This article demonstrates the potential democratising and catalysing effects of social media in relation to public discourse about mental health. Personal stories and unheard voices can be made public and shared without temporal and spatial barriers. They have significant potential to facilitate a dynamic blend of education, contact and protest. This rise in user-generated content means that collective action by individuals has the potential to influence mainstream media and policy without sole reliance on campaigning organisations. It may be that we are more likely to adjust our attitudes because of what our peers think than because of what organisations encourage us to think. The examples provided in this editorial show how citizens have asked and answered questions that organisations would not necessarily have raised.

Campaigns are increasingly incorporating social media into their communication channels, but perhaps their most important role is amplifying individual-led conversations and channelling them to mainstream media. Social media channels provide spaces for professionals to learn and share by connecting with people accessing services and colleagues. Further work should examine the relationship between social media activity and changing public attitudes to mental ill health.

\footnotetext{
Victoria Betton, PhD candidate, Institute of Communications, University of Leeds,
Leeds; Rohan Borschmann, PhD, DClinPsy, Mary Docherty, MRCP, MRCPsych, King's College London, Institute of Psychiatry, Psychology and Neurology, London; Stephen Coleman, PhD, Institute of Communications, University of Leeds, Leeds; Mark Brown, Social Spider $\mathrm{CIC}$ and One in Four magazine, London; Claire Henderson, MRCPsych, PhD, Health Service and Population Research Department, King's College London, Institute of Psychiatry, Psychology and Neurology, London, UK

Correspondence: Claire Henderson, Health Service and Population Research Department P029, David Goldberg Centre, King's College London, Institute of Psychiatry, Psychology and Neurology, De Crespigny Park, London SE5 8AF, UK. Email: Claire.1.Henderson@kcl.ac.uk

First received 1 Sep 2014, accepted 6 Nov 2014
}

\section{Funding}

C.H. is supported by a grant to Time To Change from the Government Department of Health in England and Comic Relief and is an advisor for the evaluation of the En Af Os campaign.

\section{References}

1 Dutton W, Blank B. Cultures of the Internet: The Internet in Britain. Oxford Internet Institute, 2013 (http://oxis.oii.ox.ac.uk/wp-content/uploads/2014/11/ OxIS-2013.pdf).

2 Ofcom. Facts and Figures. Ofcom, 2014 (http://media.ofcom.org.uk/facts/).

3 Kaplan A, Haenlein M. Users of the world, unite! The challenges and opportunities of social media. Bus Horiz 2010; 53: 59-68.

4 Al Ramiah A, Hewstone M. Intergroup contact as a tool for reducing, resolving, and preventing intergroup conflict. Evidence: limitations and potential. Am Psychol 2013; 68: 527-42.

5 BBC News. Asda and Tesco withdraw Halloween costume outfits. BBC News 2013; September 26 (http://www.bbc.co.uk/news/uk-24278768).

6 Corrigan P, Morris S, Michaels P, Rafacz JD, Rusch N. Challenging the public stigma of mental illness: a meta-analysis of outcome studies. Psychiatr Serv 2012 63: 963-73. 